\title{
Estimation of Daily and Weekly Variation of Global Solar Radiation in Banbatika Park
}

\author{
Kamal Bahadur Rayamajhi*
}

\begin{abstract}
Solar power meter SM-206 is used to measure the intensity of solar radiation at the horizontal surface of Banbatika Park, Rupandehi, Nepal (27.625 ${ }^{\circ} \mathrm{N}, 83.482^{\circ} \mathrm{E}$ and Alt.165m). The measurement was carried out from 7:00AM to 5:00PM in specific days for two months May and June 2019. The daily and weekly variations of global solar radiation (GSR) are studied at above mentioned site. The maximum GSR is found to be $1069 \mathrm{~W} / \mathrm{m}^{2}$ on 16th June and the minimum value is $845 \mathrm{~W} / \mathrm{m}^{2}$ on 13th May. GSR measured in the second week of May is minimum which is $854 \mathrm{~W} / \mathrm{m}^{2}$ and the maximum value $1045 \mathrm{~W} / \mathrm{m}^{2}$ is observed in the third week of June.
\end{abstract}

Key words: GSR, sun shine hours, clearness index, daily and weekly variations.

\section{Introduction:}

Solar energy is the radiant energy emitted by the sun. It is the terrestrial radiation and covers a wide frequency ranges spectrum of electromagnetic radiation. The quantity of solar energy arriving at the surface outside the earth's atmosphere is extraterrestrial radiation. The spectral distribution of radiation arriving on the earth's surface is a function of its extraterrestrial distribution and the atmospheric condition. Global or total solar radiation is the total amount of solar energy received by the earth's surface. The total solar energy in solar spectrum is useful to know the spectral distribution of the extra terrestrial radiation which would be received in the absence of the atmosphere.

The Solar radiation received by the earth as heat and light can be converted into useful thermal energy .It can be used for the production of electricity by using solar energy devices. The utilization of solar energy requires detail information on its availability. The monthly or daily averaged data are required for climatological studies and to conduct feasibility studies for solar energy systems. The data for hourly periods are needed to stimulate the performance of solar devices or during collector testing and other activities (Badescu, 2008).
The global solar radiation potential plays important role for designing and predicting the performance of solar energy equipment and solar energy potential (Sukhera \& Pasha, 1987). The total solar radiation is the fundamental input for design, optimization and performance evaluation of solar technologies and applications such as photovoltaic and solar thermal system for any specific location(Poudel et al., 2013). The solar radiation and sunshine duration are the most important variables and play an important role in the performance evaluation of renewable energy system and in many other applications like health, agriculture, construction, etc.(Gadiawala et al., 2013).

The study of solar radiation incorporates local weather condition. It is found that the higher the altitude greater the total solar radiation under the clear sky condition but under the overcast days, the solar radiation is very low in comparison to sunny days (Becker \& Bond, 1957). The solar radiant energy on the earth's surface is requirement not only in the studies of climate change, environmental pollution but also in agriculture, hydrology, food industry and promotion of overall solar energy technology programs (Iqbal, 1983).

*Lecturer, Department of Physics, Butwal Multiple Campus, Butwal, Email: rayamajhikamal501@gmail.com 
The solar radiation available in any location is affected by topography and pollution. The amount of intensity of solar radiation depends on varieties of factors such as latitude, altitude, cloud cover, season, time of day, pollution, water vapour, atmospheric effects through which the radiation is attenuated by absorption and scattering. The geographical distribution of solar radiation over a region is normally different from other regions due to position and atmospheric constituents of local weather condition (Oki \& Shiina, 2003).

Nepal is rich in solar energy. It lies in favorable insulation zone in the world. The total energy generation potential of our country will be $83000 \mathrm{GWh} /$ day (18.36 TW). This is more than present energy demand (13 TW) of the world. The average variation of global solar radiation in Nepal is from 3.6-6.2 $\mathrm{Kwh} / \mathrm{m}^{2} /$ day and sun shines for about 300 days in a year. The national average sunshine hours and solar energy are 6.8/ day and $4.7 \mathrm{Kwh} / \mathrm{m}^{2} /$ day respectively (WECS, 2010). However, the energy scenario of Nepal is alarming situation. The solar energy is the best and ultimate option among the different alternative energy sources. Solar energy is renewable and clean energy and is required to maintain the quality of human life as well as environment.

Various models have been developed by a number of researchers with a different regression coefficient for various countries and for different locations to estimate global solar radiation (Jami \& Tiwari, 2013). Angstrom (1924) proposed the first linear regression model for estimating global solar radiation. Prescott (1940) modified this model by replacing clear sky radiation with extra terrestrial radiation. This model is popularly known as AngstromPrescott model.

\section{Materials and Method:}

The Angstrom-Prescott model is the commonly used model in most of the countries including Nepal. The regression equation of this model is given by,

$\frac{\mathrm{H}}{\mathrm{H}_{\mathrm{o}}}=\mathrm{a}+\mathrm{b} \frac{\mathrm{n}}{\mathrm{N}}$

Where $\mathrm{a}$ and $\mathrm{b}$ are regression constants, $\mathrm{H}$ is monthly average daily global radiation, $\mathrm{H}_{\mathrm{o}}$ is monthly average daily extra terrestrial radiation, $\mathrm{n}$ is sunshine hours and $\mathrm{N}$ is monthly average maximum possible sunshine duration. The ratio $\mathrm{n} / \mathrm{N}$ is known as fraction of sunshine hours. It varies daily and seasonally. The ratio of solar radiation at the surface of the earth to the extra terrestrial radiation $\frac{\mathrm{H}}{\mathrm{H}_{\mathrm{O}}}$ is called clearness index or cloudless index

The monthly average daily extra terrestrial radiation on the horizontal surface given by Iqbal(1983) is $\mathrm{H}_{0}=\frac{24}{\pi} \mathrm{I}_{\mathrm{Sc}}\left(1+0.33 \cos \frac{360}{365} \mathrm{~d}\right)\left(\frac{\pi}{180} \omega_{\mathrm{S}} \sin \phi \sin \delta+\cos \phi \cos \delta \sin \omega_{\mathrm{S}}\right)[2]$

Where $\mathrm{I}_{\mathrm{Sc}}=1367 \mathrm{~W} / \mathrm{m}^{2}$ is a solar constant, $\mathrm{d}=$ day number of a year or Julian day from January 1 to December 31. (For $1^{\text {st }}$ Jan, $d=1$ and for $31^{\text {st }}$ Dec, $d=$ 365), $\phi=$ latitude of the site location, $\delta=$ declination angle and $\omega_{\mathrm{S}}=$ sunset hour angles.

The solar radiation angle is given by,

$\delta=23.45 \sin \left(\frac{360(284+d)}{365}\right)$

The hour angle is given by,

$\cos \omega_{\mathrm{S}}=-\tan \phi \tan \delta$

The maximum possible sunshine duration (i.e day length) for horizontal surface is given by, $\mathrm{N}=\frac{2}{15} \omega_{\mathrm{S}}$

Page (1961) has given the coefficients $\mathrm{a}=0.23$ and $b=0.48$ which is believed to be applicable in anywhere in the world.

The primary data of daily solar radiation on horizontal surface of Banbatika Park, Tilottama Municipality were collected by using a portable SM206 power meter. This device measures the solar radiation incident on it and displays it into digital form with the accuracy of $\pm 10 \mathrm{~W} / \mathrm{m}^{2}$ and resolution of 0.1 $\mathrm{W} / \mathrm{m}^{2}$. This solar power meter has operating temperature from $0^{0} \mathrm{C}$ to $50^{0} \mathrm{C}$. Its special features are low noise, high resolution and low power consumption. It works in all weather conditions.

The measurements were carried out at the selected location from 7AM to 5PM in clear sky in specific days for two months May and June 2019. The 
solar power meter was kept on the wooden stand at a height of $1.5 \mathrm{~m}$ and tilted towards the sun. The amount of solar radiation incident on a solar collector is strongly affected by its installation angle and orientation (Koussa et al., 2016). The readings of global solar radiation were taken in the interval of half an hour. The collected data were tabulated, processed and analyzed.

\section{Result and discussion}

The daily global solar radiation data are presented in table 1 . The relation between observed and estimated values of global solar radiation of Banbatika park is shown in figure 1.

The intensity of solar radiation depends on altitude, latitude, aerosol and weather condition of the sky. The maximum global solar radiation is found to be $1069 \mathrm{~W} / \mathrm{m}^{2}$ on 16th June and the minimum value $845 \mathrm{~W} / \mathrm{m}^{2}$ is observed on 13 th may 2019. The plot shows that there is a close agreement between the measured and estimated values of solar radiation in Banbatika Park. The estimated values of GSR are comparatively higher than the measured values.
Table 1 : Average global solar radiation data at Banbatika park in different days of May and June.

\begin{tabular}{|l|c|c|c|}
\hline Day & Julian day (d) & Hobs (w/m $\mathbf{~})$ & He (w/m $\mathbf{~})$ \\
\hline May 10 & 130 & 860 & 897 \\
\hline May 13 & 133 & 845 & 875 \\
\hline May 14 & 134 & 857 & 886 \\
\hline May 19 & 139 & 858 & 893 \\
\hline May 20 & 140 & 863 & 855 \\
\hline May 21 & 141 & 874 & 938 \\
\hline May 28 & 148 & 953 & 979 \\
\hline May 29 & 149 & 908 & 948 \\
\hline May 31 & 151 & 940 & 880 \\
\hline June 1 & 152 & 1007 & 1027 \\
\hline June 4 & 155 & 997 & 1032 \\
\hline June 5 & 156 & 1012 & 1049 \\
\hline June 10 & 161 & 987 & 1011 \\
\hline June 11 & 162 & 998 & 1022 \\
\hline June 12 & 163 & 1018 & 960 \\
\hline June 15 & 166 & 1028 & 1095 \\
\hline June 16 & 167 & 1069 & 1157 \\
\hline June 17 & 168 & 1040 & 1123 \\
\hline
\end{tabular}

Source: Field survey 2019.

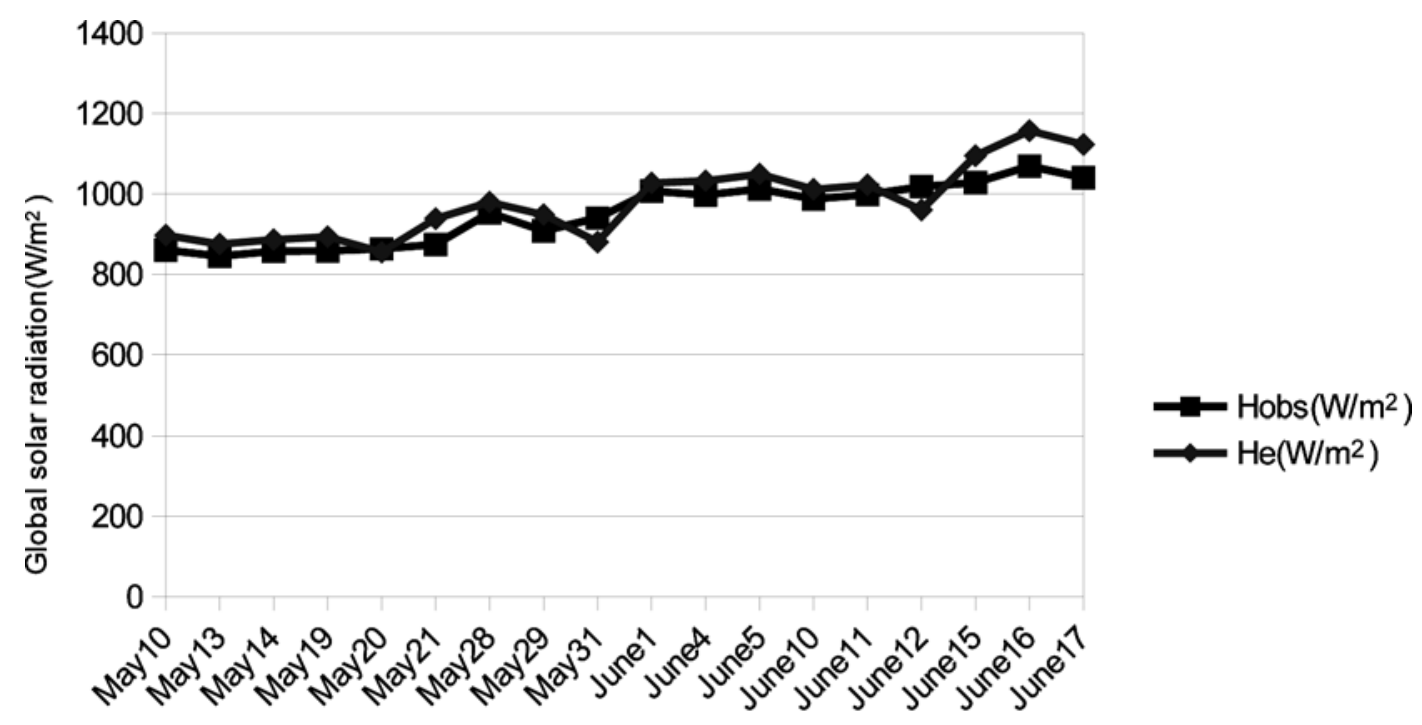

Day

Figure 1 : Comparison between measured and estimated values of global solar radiation at Banbatika Park, 2019. 
The average GSR data of Banbatika Park in different weeks of May and June is presented in table2. The weekly variation of GSR in Banbatika park is shown in figure 2 . The highest global solar radiation is observed in the third week of June which is 1045 $\mathrm{W} / \mathrm{m}^{2}$. The lowest value of GSR is $854 \mathrm{~W} / \mathrm{m}^{2}$ observed in the second week of May which is due to the presence of cloud in the sky and less intensity of solar radiation reaching on the site.
Table -2: Average GSR at Banbatika Park in different weeks of May and June.

\begin{tabular}{|c|c|c|c|}
\hline Month & Week & $\mathbf{H m}\left(\mathbf{w} / \mathbf{m}^{\mathbf{2}}\right)$ & $\mathbf{H e}\left(\mathbf{w} / \mathbf{m}^{\mathbf{2}}\right)$ \\
\hline May & 2nd & 854 & 886 \\
\hline May & 3rd & 865 & 895 \\
\hline May & 4th & 934 & 936 \\
\hline June & 1st & 1005 & 1036 \\
\hline June & 2nd & 1001 & 998 \\
\hline June & 3rd & 1045 & 1125 \\
\hline
\end{tabular}

Source: Field survey 2019

The plot shows that the estimated value of GSR is minimum in the second week of May which is 886 $\mathrm{w} / \mathrm{m}^{2}$ and the maximum value is $1125 \mathrm{~W} / \mathrm{m}^{2}$ in the third week of June. It is found that the measured and estimated values are closely related to each other.

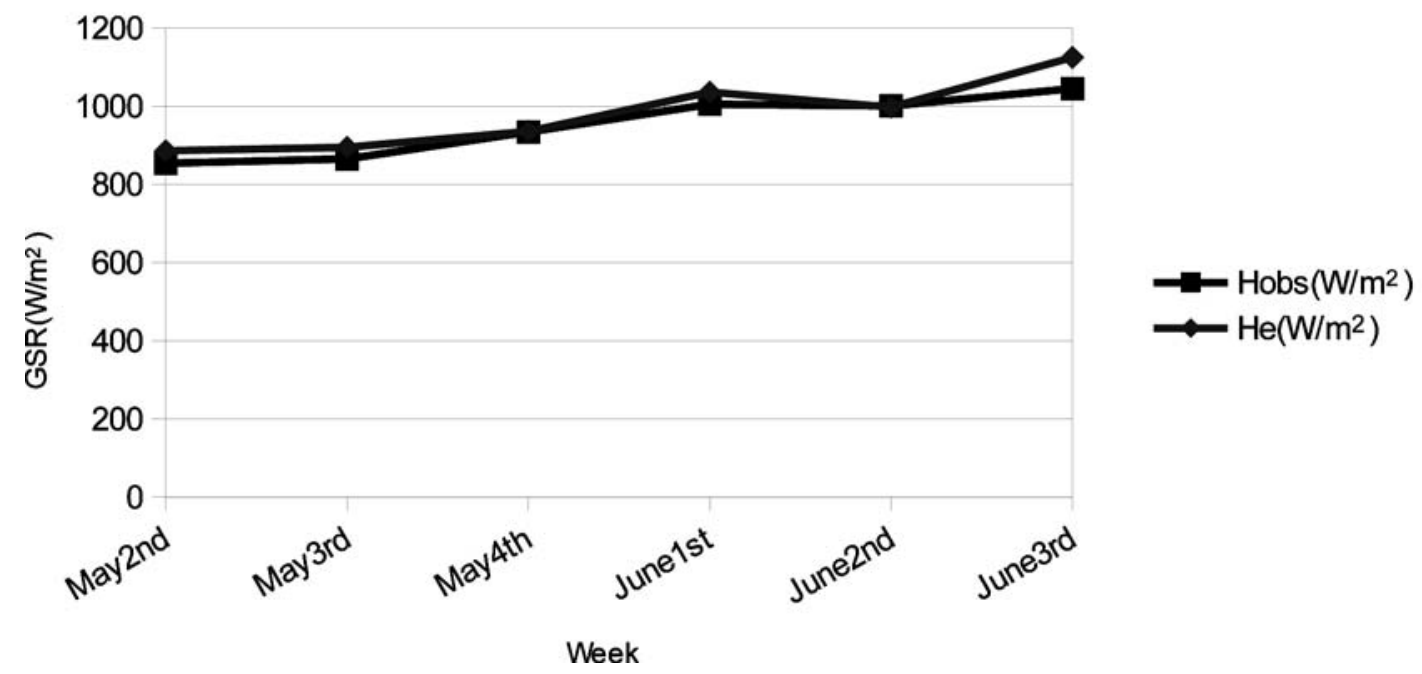

Figure 2: Weakly variation of observed and estimated GSR in Banbatika Park, 2019.

\section{Conclusion}

The global solar radiation varies daily as well as weekly. The maximum value of daily global solar radiation is found to be $1069 \mathrm{~W} / \mathrm{m}^{2}$ on 16th June and minimum value is $845 \mathrm{~W} / \mathrm{m}^{2}$ on 13 th May 2019 . The global solar radiation observed in the second week of May is minimum which is $854 \mathrm{~W} / \mathrm{m}^{2}$ and maximum value $1045 \mathrm{~W} / \mathrm{m}^{2}$ is measured in the third week of June. The aerosol and local weather condition affect the global solar radiation. The available data are relevant as well as sufficient to explore solar energy even in rainy season. There is a close intimacy between measured and estimated values of global solar radiation. 


\section{References}

Angstrom, A. (1924). Solar and terrestrial radiation, Quartz.J.Roy., Meteo. Soc., 50, 121-125. Badescu, V. (2008). Modelling Solar Radiation at the Earth's Surface Recent Advances. Springer Publication, Germany.

Becker, C. F. \& Boyd, J. S. (1957). Solar radiation availability on surfaces in the United States as affected by season, orientation, latitude, altitude and cloudiness, J. Solar Energy, 1(1), 13-21.

Gadiwala, M. S., Usman, A., Akhtar, M., \& Jamil, K. (2013). Empirical Models for the Estimation of Global Solar Radiation with Sunshine Hours on Horizontal Surface in Various Cities of Pakistan, Pakistan Journal of Meteorology, 9 (18), 43-49.

Iqbal, M. (1983). An introduction to solar radiation, Academic Press New York.

Jamil, M. \& Tiwari, G. N. (2010). Solar Radiation Models Review, International Journal of Energy and Environment, I (3), 513-532.

Koussa, M., Saheb koussa, D. \& Hamane, M. (2016), Effect of a Daily Flat plate Collector Orientation change on the Solar System Performances, Proceeding of the IEEE 7th International Renewable Energy Congress(IREC), Hammamet, Tunisia.

Oki, M. \& Shiina, H. (2003). Preliminary Study on an Estimation Method for Annual Solar Irradiance at Various Geographical Altitude, Eighth International Conference, Neitherland, 11-14.

Page, J.K. (1961), Proceeding of UN Conference on New Source of Energy, Vol. 4, 378.

Poudyal, K. N., Bhattarai, B. K., Sapkota, B. K., Berit, K. \& Karki, N. R. (2013). Estimation of Global Solar Radiation Using Pyranometer and NILU-UV Irradiance meter at Pokhara Valley, Pokhara, Journal of the Institute of Engineering, vol. 9, 69-78.

Prescott, J. A., (1940). Evaporation from water surface in relation to solar radiation, Tran, Roy, Soc. So. Aust., 64, 114-118.

Sukhera, M. B. \& Pasha, M. A. R. (1987). Solar radiation maps for Pakistan, J. Solar and Wind Technology, $4(2), 229-238$.

WECS. (2010). Energy Sector Synopsis Report Nepal, Kathmandu: writer. 